\title{
The Approach to the Chinese Diplomatic Discourse
}

\author{
Alexander Semenov ${ }^{1} \cdot$ Anatoly Tsvyk $^{2}$ iD \\ Received: 13 December 2019 / Accepted: 17 April 2021 / Published online: 27 April 2021 \\ (c) Fudan University 2021
}

\begin{abstract}
This research article aims to examine the problem of comprehending Chinese diplomatic discourse. We argue that China's diplomatic discourse is a multilevel and complicated system underpinned by figurative and symbolic semantics, divergent translations into foreign languages, multidimensionality of the cognitive sphere and versatility of communication. The discussions of well-known Chinese scholars on the issue of comprehension of China's diplomatic discourse are highlighted in the article. We also analyze the concept of a "shared future for humankind," which is the systemic core of China's diplomatic discourse today and represents a brand of a global worldview promoted by Chinese leadership. We examine this concept using sociolinguistic, cognitive and pragmatic approaches.
\end{abstract}

Keywords China $\cdot$ Foreign policy $\cdot$ Discourse $\cdot$ Diplomacy $\cdot$ Community of shared future for humankind

\section{Introduction}

I know you think you understand what you thought I said but I'm not sure you realize that what you heard is not what I meant

- Alan Greenspan.

Since his ascendance to the presidency in 2013, foreign policy steps of Chinese President Xi Jinping in the international stage have given evidence of China's shift from regional goals to global ones in international affairs. In global economy, China

Anatoly Tsvyk

a.tsvyk91@mail.ru

Alexander Semenov

legatus@bk.ru

1 Department of Oriental Languages, Diplomatic Academy of the Ministry of Foreign Affairs of the Russian Federation, Moscow, Russia

2 Department of Theory and History of International Relations, Peoples' Friendship, University of Russia, (RUDN University), Moscow, Russia 
is taking the lead. China has been emerging as an increasingly stronger economic power of global scale and has been taking action to boost its political role on the international stage, its political weight has not been seeing an automatic and commensurate growth. The global foreign policy field, including its information space, has been vastly dominated by the discourse of Western countries.

China, despite its "major country diplomacy" (as it is defined by Chinese authorities), was still de facto blocked in East Asia in the information sphere. Attempts to go beyond the boundaries of that region boiled down only to Beijing's more intense activity in those countries where the Chinese community is the biggest.

Professor of the University of Macau Wang Jianwei in his article notes, Xi Jinping is particularly fond of enhancing China's discourse power in international relations which has long been dominated by "Western concepts and theories of international relations" (Wang 2018).

Thus, it was the awareness that China's impact and image in the global arena depend not only on its economic achievements, but, possibly, to a larger extent, on the capability to talk about those achievements, giving them one's own interpretation, and to make oneself heard and to propose one's own agenda to the world. From that moment, the "linguistic turn" in China's foreign policy has begun.

At the initial stage, issues of the country's presentation in the world and of building China's image abroad were analyzed at the level of experts. Experts pointed out to an essential role of the discursive approach to the activities in the international field. When addressing that challenge, Chinese analysts proceeded from practical goals and treated discourse in the sociolinguistic vein. The notion of "discourse" they conveyed as huayu (话语) (lit.: “spoken language”).

The concept of "discourse" is polysemic, so, for now, there is no single definition that everybody would accept. Nevertheless, discourse is based on a communicative phenomenon, and this is a premise that all researchers subscribe to. They begin to differ when the foundation of discourse needs to be "completed" in order to have a comprehensive definition depending on a particular science.

Diplomatic discourse determines communication of institutions as subjects in the professional and public areas for the attainment of a country's goals in foreign policy.

China's diplomatic discourse is the way Chinese diplomacy speaks (language aspect), what it understands (cognitive aspect) and what goals it sets (pragmatic aspect).

In the Chinese interpretation, to become entitled to talk-i.e., to "get the right to a discourse" 话语权 huayuquan-in international language space is equivalent to being able to “assert the power of one's discourse" (话语权一huayuquan). The thing is that in the Chinese language, the notions of "rights" 权利 quanli and “power” 权力 quanli sound the same and are practically written the same way, with only the second hieroglyphs in binomials differing. Thus, transition from a right to power may be not a process but, rather, a subjective decision of a leader in a particular situation.

After Xi Jinping came to power in 2012, China's top leadership also joined in the "battle for discourse." In November 2013, at the Third Plenary Session of the 18th Central Committee of the Communist Party of China, "The Decision on Major 
Issues Concerning Comprehensively Deepening Reforms" was adopted, which emphasized the need to reinforce opportunities for dissemination of information overseas, building a system of entitlement/power to foreign policy discourse and promoting the entry of Chinese culture into a wider world.

On December 30, 2013, during the 12th collective training session of members of the Political Bureau of the CPC Central Committee, Xi Jinping stressed that in order to enhance soft power of the nation's culture, efforts should be made to reinforce entitlement/power to international discourse. To open up new opportunities for dissemination of information overseas, a system of foreign policy discourse needs to be carefully built, harnessing creatives force, inspiration and public trust. One strategic goal of those endeavors is to increase China's entitlement/power to international discourse.

As time went by, the issue of China's foreign policy discourse has remained vital until today. Individual aspects of that issue gave rise and still give rise to heated debate.

The subject of discussion in the Chinese expert community was a number of issues.

First, what is the reason for the lack of understanding of Chinese diplomatic discourse by Western countries?

Second, is China's diplomatic discourse difficult to comprehend and should it be?

In this context, it is necessary to overview and identify key approaches of Chinese experts to the issue of comprehension of China's diplomatic discourse.

\section{Discussions on China's Diplomatic Discourse}

\subsection{Object of Academic Discussions}

In 2015, the Shanghai-based Internet news portal "Pengpai Xinwen" published an article by Dr. Zhang Feng (张锋), Senior Lecturer at the Department of International Relations of Australian National University, entitled "Why It Is So Hard to Comprehend China's Diplomatic Discourse."

Zhang raised a problem of discrepancies between the representations of the international worldview by the West and by China. He discussed mutual lack of understanding based on the language, cognitive and pragmatic planes.

\subsection{Sociolinguistic aspect}

From the language perspective, Zhang believes China's diplomatic discourse brings up formulas with semantically obscure and vague meanings. For instance, the notion 合作共赢 hezuo gongying (“win-win cooperation”), which lies in the core of a "new type of international relations" promoted by Chinese leadership, is vague, obscure and does not explain what moves Chinese diplomacy is going to make. In Zhang's opinion, other discourse formulas, such as 义利观 yiliguan (“viewpoint on justice 
and interests"), 命运共同体 mingyun gongtongti (“community of shared future"), also require a concrete definition and refinement (Zhang Feng 2015).

\subsection{Cognitive aspect}

From Zhang's point of view, lack of comprehension with respect to diplomatic formulas does not result purely from difficulty of the Chinese language. After all, there are quite a lot of people who know China and Chinese culture well in the West.

For a few millennia, China has cultivated an integral thinking paradigm. The Chinese included the singular into the common. On the contrary, people of the West made an emphasis on the singular, on the individual. Therefore, when Chinese diplomacy says that China's upswing is a good thing that can benefit the entire world, the West, based on its individualistic worldview, believes that this declaration smells of trickery and intention to conceal selfish motives.

Proposing global projects such as the "Belt and Road Initiative," China often uses the hieroglyph 共 gong (“common") in its discourse formulas: 共商 gongshang ("to discuss together"), 共建 gongjian (“to build together"), 共享 gongxiang (“to use together"). The Western world believes them to be rather vague and veiling China's selfish gain.

\subsection{Pragmatic aspect}

In the opinion of Zhang, this plane reveals itself most prominently in the relations between China and the USA. It is worth noting that the author considered the SinoAmerican relations before their deterioration in 2018.

For instance, before the trade war had began, China wanted to establish with the USA a "new type of great power relations" that would behoove both nations, emphasizing three aspects:

First, China and the USA have no conflict with and are not opposed to one another. The Americans comprehend this discourse formula, but they doubt whether it is viable.

Second, China and the USA respect each other's vital interests. The Americans comprehend this discourse formula even better, but they cannot accept it, because certain vital interests of China can prejudice US strategic interests. In their opinion, if this premise should be accepted, it would be a big concession to Chinese diplomacy.

Third, collaboration and a win-win situation between China and the USA. The Americans do not comprehend this discourse quite well, as it does not explain what goals China seeks to achieve and what its interests are. Therefore, they consider this premise hollow and without substance, unworthy of any reaction or serious attention.

Thus, a discourse strategy of "new type of Great Power relations" is a clichéd notion that expresses China's ambition, but large-scale outreach campaigns will be required to fill it with a real meaning, Zhang argues. As a result, China is weary of 
giving explanations, America is weary of hearing explanations, a lot of time has passed, and all interest in that formula has been lost.

The author believes that the communicative "gap" can be closed with proper investigation of the partner's mental peculiarities. The Americans' comprehension operates best when their own interests are at play, so, when one communicates with them, distribution of interests needs to be put on the agenda.

Furthermore, free communication depends on taking into account peculiarities of one's communicative partner, on the choice of relevant discourse strategies and on a particular time of communication.

Zhang gives specific recommendations for Chinese leadership in how to build diplomatic discourse with respect to Asian-Pacific nations:

- The USA is mostly concerned about its interests in the Asian-Pacific region, so, above all, distribution of interests in the region needs to be discussed;

- Australia maneuvers between the USA and China, so, basically, in diplomatic discourse with respect to Australia, emphasis should be made on China taking concrete measures in order to ensure stability of the Chinese-American relations;

- Southeast Asian countries are concerned with the situation in the South China Sea, so the way China manages and controls territorial disputes should be a matter of discussion;

- A red line should be drawn in the relations with Japan;

- With the countries that accept China's win-win ideas and are involved in the cooperation project of the Belt and Road Initiative, the "win-win" discourse needs to be promoted even further, and China's particular policies need to be explained.

The Chinese scholar arrives at the conclusion that not only the world should comprehend China, but China should do its best to seek the world's comprehension. The power of persuasion is an element of international influence of states and the goal that Chinese diplomatic discourse needs to aspire to attain.

Another Chinese expert, Su Changhe (苏长和), professor at the Department of Diplomacy, School of International Relations and Public Affairs, Fudan University, believes that rather often one can hear that in international communication, people abroad cannot understand Chinese official political or diplomatic discourse, that they consider discourse formulas hollow and without substance, so they suggest that everyone express themselves in a comprehensible language of "progressive international community."

$\mathrm{Su}$ believes that a discursive system built on an international language, political notions, terms, names is an element of a state's cultural sovereignty, and a nation must defend its sovereignty, expressing itself in its own language ( $\mathrm{Su} 2015$ ).

For $\mathrm{Su}$, the issue of lack of comprehension of discourse is predetermined by a difference of languages, and its resolution belongs to the plane of intercultural communication. However, when different cultures communicate, mutual influence that can be strong or weak plays a role. A strong culture, based on its own standards, explains a weaker one. By imposing its discourse, it creates a center of attraction 
for the educated class, but, because of asymmetry and imbalance of interaction, the abundance of national discourse remains untapped.

Thus, lack of comprehension is not a historical defect of Chinese political and diplomatic discourses, but reflects domination of a foreign, in this case Western, discourse, and unwillingness of its proponents to comprehend peculiarities of China's internal discourse. In that respect, studies of the Chinese language and culture will promote mutual understanding between China and the West and will help avoid "communication breakdowns and failures."

$\mathrm{Su}$ believes that Chinese diplomatic discourse has potential to enrich the world with new categories, notions and formulas. In reality, China has given global diplomacy a number of discourse formulas, without which it is hard to comprehend its foreign policy: “Five Principles of Peaceful Coexistence" (和平共处五项原则), the “Belt and Road Initiative" “representative democracy” (协商民主), “peaceful development” (和平发展), etc.

As China's influence grows, discourse needs to be amended, transforming Chinese-type categories and notions into commonly used ones. And then, the issue of comprehending China's diplomatic discourse will gradually fade away.

Thus, experts of this group (Zhang Feng, Su Changhe) all concur that there are difficulties with comprehending Chinese diplomatic discourse, and for a foreign policy to be successful, communicative lack of understanding should be overcome. However, Zhang suggests switching fully to Western diplomatic discourse and openly speaking about China's intentions. Su thinks that China should rely on its own diplomatic discourse, which protects the country's cultural sovereignty, that for partners, comprehension of China's diplomacy presents no difficulty, and let the West pay for its own education, and let it achieve comprehension of the logic and style of Chinese narrative completely on its own.

\subsection{It is Not Difficult to Comprehend, and There Should be No Difficulties with Comprehension}

Xu Jin (徐进), Head of the International Politics Theory Division, and Research Fellow, Institute of World Economics and Politics (IWEP), Chinese Academy of Social Sciences (CASS), engaged into a dispute with the scholars of the first group.

He does not think that Chinese diplomatic discourse is hard to comprehend.

First, it is the West that complains of lack of comprehension, but non-Western countries, like Russia, have no difficulty comprehending China's discourse formulas.

Second, formulas of Chinese diplomacy, such as "relations of a new type between great powers" "win-win cooperation," are no harder to comprehend than terms of American diplomacy, such as "shareholders and stakeholders" or "coevolution." And Chinese diplomats, trying to reveal the semantic meaning of American formulas, have not complained of being weary.

Third, no country has been able to convince the world of anything-it's "mission impossible." 
Fourth, for Zhang Feng, to convince the world means to convince the West. Quoting Michel Foucault who said that "discourse is power," Xu believes that diplomatic discourse reflects interests of Western countries, and, with China seeking the right to define and interpret notions, ideas and rules of international relations, the West will use all means in an attempt to maintain its power in international discourse, including by feigning lack of comprehension, by complaining and accusing ( $\mathrm{Xu} 2015$ ).

Moreover, $\mathrm{Xu}$ lifts the issue of lack of comprehension of a discourse. He distinguishes between a professional diplomatic discourse and a public diplomatic discourse. He believes that discourse formulas pertain more to the professional sphere. And diplomatic discourse is a signal that aims not so much to persuade the other side as to demonstrate a political stance and to implicitly point out to principles and a vector of actions. And, at the end of the day, effectiveness of Chinese diplomacy must be evaluated not so much by words as by actions.

Thus, $\mathrm{Xu}$ does not think that Chinese diplomatic discourse is hard to comprehend, it is the West that creates a problem, as it feigns lack of comprehension for the sake of its own interests. Discourse must not be difficult either, because Western countries will not be able to determine whether China's words are compatible with its actions, which can generate errors in strategy.

\subsection{It is Difficult to Comprehend, and There Should be Difficulties with Comprehension}

Joining the debate with experts of the first group, Zhang Zhizhou (张志洲), a senior researcher at the Center for Public Diplomacy Studies and the Collaborative Innovation Center of Overseas Promotion of Chinese Culture, Beijing Foreign Studies University, believes that the issue of diplomatic discourse is not new and has been discussed by specialists. Examples of so-called ambiguous discourse formulas, such as "collaboration and win-win situation" and "relations of a new type between large countries," were not given correctly enough in reality, because the "collaboration and win-win situation" formula has roots in traditional European culture, namely in the "win-win strategy," and variations of the formula "relations of a new type between large countries" were used by both President Barack Obama and by Secretary of State John Kerry back in the day. In the first case, what should have been done was not to give an abstract formula but to find out: "In what spheres should cooperation be performed and what win-win could be gained?," and, in the second case, differences between large states-China and the U.S. - depend not so much on vagueness of formulas or uncertainty of foreign policy as on perennial problems with mutual trust and intertwining of interests (Zhang Zhizhou 2015).

Zhang supports Feng Zhang's viewpoint that Chinese diplomatic discourse is lacking concrete definition and refinement and believes that only comprehension in the external world will help discourse to be identified and to be transformed, going forward, into soft power of foreign policy. He believes that Chinese diplomatic discourse is lacking accurate and focused dissemination in the world.

In Zhang's opinion, the issue of lack of comprehension of Chinese diplomatic discourse arose in the external world-external with respect to the People's Republic of 
China. A higher status in international relations and an increasing intertwining of mutual interests lead to a closer interrelation of China and the West, which implicates openness and transparency of relations. If there is a lack of comprehension of diplomatic discourse, then, notwithstanding all lofty rhetoric and right moves, influence will erode and legitimacy of foreign policy will be challenged. Therefore, the issue of lack of comprehension of diplomatic discourse should not be underrated.

Zhang builds his analysis of this issue through a connection and contrast of general semiotic oppositions: Chinese/external, central/peripheral.

First, the issue of lack of comprehension is linked to an integral discursive system consisting of two components-Chinese and foreign (Western). Over the past few decades, Chinese discourse has been steadily evolving. A revolutionary discourse shaped into formulas, such as anti-imperialism, anti-colonialism, anti-hegemony, has been falling into oblivion and has been gradually replaced by Western discourse with its general notions shaped into terms, such as principle, line, course, policy, and concrete formulas pertaining to state affiliation, region and sphere of activity. The disparity between cultural traditions and ways of thinking of the West and the East, and also a gap between words and practical actions were exactly the factors that caused difficulties in comprehending Chinese discourse. On the language plane, an exact translation equivalent of a Chinese word or concept cannot always be found. In foreign policy, explanations were not always given, fine-tuning and required interpretation were lacking. Thus, obstacles for comprehension were created in the context of a foreign language culture.

Second, the true reason for the difference between ways of thinking manifested in diplomatic discourse is a conflict of civilizations and differences in cultural traditions and systems of values of China and the West. But even this premise, in Zhang's opinion, is not absolute. Meeting with Chinese representatives at different levels, Western politicians often used quotes from Chinese classical treatises, idiomatic expressions and maxims that could be easily understood, unlike diplomatic discourse. In reality, the West often passes its attempts to predict intentions and goals of China's foreign policy as inability to comprehend discourse, and actions like that go beyond cross-cultural differences.

Third, looking at the issue of lack of comprehension from the customary angle of the West-run world order, China needs to prove legitimacy of its foreign policy. Vagueness and ambiguity of diplomatic discourse may stem from differences in the sphere of culture and thinking, but can also be an example of diplomatic tactics, in which furtive hints, latent meanings, metaphors and even methods of Chinese spiritual and physical practices called "Taijiquan" are normal and common to diplomacy of all states, including China.

China's diplomatic intentions do not find comprehension in the West. In Western discourse, China's upswing looks like a challenge to national interests of Western countries or as a threat to the international order run by Western nations. Therefore, China's active foreign policy generates a deep-seated distrust in the West, willingness to make Chinese diplomacy "open," "generally comprehensible," "completely understandable," and a requirement that it needs to confirm its legitimacy.

Fourth, Chinese diplomatic discourse must reflect China's thoughts about international relations. By engaging into a debate with those who are trying to address 
the issue of lack of comprehension of Chinese discourse solely through a clear-cut definition of relations and interests, Zhang believes that this standpoint only oversimplifies the problem.

Over more than two decades, the system of diplomatic discourse in China has embraced a lot of Western notions, categories and formulas. Ways of perception, ideas and notions, the logic of thinking, a take on the truth, such as the discourse of counterterrorism efforts, state interests, soft power, globalization used by American scholars in the area of international relations, produced a deep impact on formulas of Chinese diplomatic discourse. That impact had its positive sides, but also was hiding traps set by Western discourse. One of those traps was one-dimensional and oversimplified thinking in the area of international relations.

As Zhang notes, as American hegemony was taking shape, discourse played an important role in the process. Without support by discourse, a material force would not have been able to lay a foundation for hegemony in a natural way. One can say that American hegemony is hegemony of discourse. It is possible to borrow American discourse, but, as China was following it without critical evaluation, it de facto was involved in building a stable hegemony of US discourse.

Zhang is convinced that American discourse, and, in a broader sense, Western discourse, reflects their respective interests, culture and thinking. To become a global power, China needs to be independent in expressing its interests, and, in foreign policy, it must address more frequently the cultural traditions accumulated by the Chinese civilization over a few millennia. And diplomatic discourse must express its thoughts about international relations. If it is reasonably "hard to comprehend," it will be all for the better.

Thus, Zhang is among those who believe that China's diplomatic discourse is genuinely hard to comprehend. However, in terms of values, Zhang suggests keeping all discursive difficulties, backing up independence and originality of Chinese discourse and thinking, refraining from borrowing the West's diplomatic strategies and from facilitating reinforcement of American hegemony.

We can thus conclude that the Chinese expert community is lacking consensus regarding the question whether Chinese diplomatic discourse is hard to comprehend by Western countries and what exactly it should be.

\section{Community of Shared Future for Humankind"人类命运共同 体 Renlei Mingyun Gongtongti as a One of the Basic Concepts in China's Diplomatic Discourse}

We suggest analyzing the concept 人类命运共同体 (“community of shared future for humankind"), which is the systemic core of China's diplomatic discourse today and represents a brand of a global worldview promoted by Chinese leadership. This concept has never been described in specific detail and remains obscure for the international academic and expert community. As Chinese scholar Zhao Xiaochun notes, it can be seen that the call for building a community of shared future marks the beginning of China's global activism (Zhao 2018). 
Combining the terms of "destiny/future" and "community" and forming the idea of a "community of shared future" generates a powerful plastic concept, the intellectual roots of which are found by some in Western works, others in traditional Chinese culture, still others in communist ideas of the past, and still others in modern socialist ideas with Chinese characteristics.

Thus, the German researcher J. Mardell believes that the intellectual connection of the idea of a "community of shared future" leads to the work of Ernest Renan, the French philosopher and writer of "What is a Nation," in which he assumed that nations are connected not so much by ethnicity and common culture but by a deep sense of community and shared destiny/future (Mardell 2017). Chinese scholar Guo Yezhou notes that the idea of a "community of shared future for humankind" demonstrates a high degree of unity and organic integration of the ideas of traditional Chinese culture shijie datong (harmony between heaven and humanity), tianxia yijia (Celestial Empire as one family) and trends of the modern era (Guo 2018). According to Liu Hungang, associate professor at Xiamen University, this idea is intellectually connected with the communist society according to K. Marx and F. Engels, which is the community of free people and which at the present stage represents socialism with Chinese characteristics. Guo Zhang, professor of philosophy at the Institute of Philosophy of the People's University, claims that Karl Marx uses many concepts related to community in his works: natural, primitive, tribal, national, social, etc. Believing that development proceeds from a natural community to a capitalist and further to a communist one, Professor Guo Zhang argues that the creation of a community of shared future is a transitional period to a community of free people, that is, to the communist stage of history. Chou Chaobin, senior researcher at the US Research Institute of the Civil Society of the People's Republic of China, believes that the idea of a "community of shared future for humankind" is a concrete practice of building socialism with Chinese characteristics in a new era.

Many Western researchers are skeptical about the concept of a community of shared future for humankind, considering it complex, incomprehensible, and used on purpose to obscure the essence of the issue. In fact, in our opinion, this term is well thought out, structured, and the application of each new formulation has a farreaching goal (Zhang 2018).

We suggest using three approaches for analyzing our case (人类命运共同体 renlei mingyun gongtongti). These are (1) sociolinguistic approach (how to translate it and which interpretation does it have); (2) cognitive approach (how to understand it); (3) pragmatic approach (its promotion and implementation).

\subsection{Sociolinguistic Approach}

We suggest analyzing this concept within the framework of a hermeneutic circle: from individual parts to a whole and from a whole to individual parts.

人类命运共同体 (renlei mingyun gongtongti) consists of three concepts: 人类 (renlei)—“humankind/humanity,” 命运 (mingyun)—“destiny” (“future”) and 共同 体 (gongtongti)_“community." 
Etymologically, the layer of the "humankind" concept in the Chinese language is rendered by two hieroglyphs: 人 ren—“human" and 类 lei-“kind," i.e., their combination means "humankind." "Humankind" (or "humanity") is the contemporary actualization of this binomial.

The concept of "destiny" in the Chinese language is designated by two hieroglyphs 命运 (mingyun), with both of them playing an important role in understanding the word meaning.

Merging 命 ming and 运 yun within one concept 命运 mingyun produces the meaning "fate," "destiny," with an underlying meaning of "movement of life," "circle of life." Life metamorphoses can change life, destiny 改命 gaige, or one can lose life, or what in ancient times was called Tianming, or Mandate of Heaven一革命 geming. A change of the life/destiny paradigm is the result of operations of Heaven, supernatural forces or an order from above, as a reaction to a correct or incorrect moral conduct.

It should be noted that the morpheme 革命 geming, "destiny," does not have a fatalistic meaning in Chinese tradition, unlike the Russian notion of "destiny" [sud'ba] or English “destiny.” 革命 geming, or destiny in Chinese, is a changeable life path into the future, which can be adjusted.

But as Cao notes, the word "destiny" in English implies a lack of choice along a pre-determined trajectory of (only) China's making and was perceived as generating resistance to Chinese initiatives in some quarters (Cao 2017).

Therefore, the Central Compilation and Translation Bureau under the Central Committee of the Communist Party of China suggested at first, when translating into English, the meaning "destiny," and after a few years of the concept test-run, the final translation equivalent was approved as "future."

The concept "community" consists of the morpheme 共同 gongtong (“common," “joint") and 体 ("body," "shape," “form," “structure," “formation"), i.e., 共同体 gongtongti means "form" or "structure of common," "structured or formed common,” i.e., “community.” In English: community - common + unity.

Analysis of the concept 人类命运共同体 renlei mingyun gongtongti on the sociolinguistic plane showed that because of peculiarities of the hieroglyphic logographic writing system, there are certain difficulties in the concept evolution and its transformation into a monosemic term. Polysemy, inherent to the concept, manifests itself especially remarkably in translations into foreign languages, with different languages seeing shifts of emphases within the concept or even an expanded lexical interpretation-probably, for political or ideological reasons.

Being aware of an unfinished state of the concept 人类命运共同体 renlei mingyun gongtongti, Chinese leadership, this time on the cognitive plane, made an effort for its further structuring and creating a relevant concept sphere.

\subsection{Cognitive Approach}

On the cognitive plane, ideas, concepts, notions and values are identified, classified and structured, thus creating a cognitive sphere. 
A cognitive sphere is an open system built as a hierarchy where lower items are subjected to higher ones. It has an external side and an internal side. As it unfolds outward, a cognitive sphere can be an element of a wider cognitive space.

The internal structure of a cognitive sphere can be represented as a "pyramid" or a "tree."

The management system of a cognitive sphere has flexibility due to frames, or basic ideas/images, concepts, notions, values. Frames are integrated into a cognitive sphere vertically and horizontally. They are flexible, and, in the course of mental activity, images, through concepts, transform into notions, with ideas/ images also serving as the foundation of basic values.

Essential historical frames are attached to a cognitive sphere, to impart temporal depth and volume to a cognitive space.

As language analysis showed, the cognitive sphere of 人类命运共同体 renlei mingyun gongtongti, "shared future for humankind," consists of three basic concepts: "common," or "community," "future/destiny," and "mankind/humanity." Frequently, linguistic interpretation and translation into foreign languages change accents in phrases and, as in this case, in a compound concept.

As the compound concept evolved, its cognitive sphere was expanding and each element was acquiring lower-level components.

The main frame-“community"-was fleshed out by a variety of images and metaphors:

- Chinese leadership also uses the concept of "global village” 地球村 diqiuqun (living in individual dwellings, but within the boundaries of one village, and there are common ties and interests linked to that notion) as an important node of the cognitive sphere;

- “under a common blue sky, in a shared home” 同一个蓝天下, 同一个家园 tong yi ge lan tian xia, tong yi ge jiayuan (meeting with representatives of political parties from all over the world, Xi Jinping said that destinies of all peoples in today's world were closely connected and all of them depended on one another, as though they lived in one shared home);

- “big family”一大家庭 da jiating (a metaphor of a closer interaction between the world's nations);

- “one world”一世界大同 shijie datong, "harmony between heaven and humanity” - 天人合一 tianren heyi (Zhang 2018).

Matrimonial bonds are the highest representation of commonality. Quoting from the Me and You Verse of Guan Daosheng (1262-1319), a well-known artist and calligrapher who lived during the early Yuan Dynasty: 你中有我, 我中有你 $n i$ zhong you wo, wo zhong you ni "Now you are in me/And I am in you," Xi Jinping was painting a picture of an inextricable and inseparable bond of two spouses as an example of humankind's integration for the sake of common future.

The frame "future" is described by the following images:

- 美丽未来 meili weilai “beautiful future” (the most general notion), 
- the ideal of the "beautiful tomorrow" - it is "a great unity in the world and the Heavenly Empire as one family"- the "golden age" metaphor from China's history.

The frame "humankind" emphasizes people's unity in the world:

- 人类只有一个地球, 各国共处一个世界 renlei zhi you yi ge diqiu, ge guo gongchu yi ge shijie "humankind has only one Earth, and all nations exist all together in one world" (a phrase that denotes the world's unity, but also means separate existence of nations).

The figurative and metaphoric dimension of the cognitive sphere 人类命运共同 体 renlei mingyun gongtongti, "shared future for humankind," is supplemented with evolution of the conceptual framework.

Xi Jinping's statement entitled "Working Together to Forge a New Partnership of Win-win Cooperation and Create a Community of Shared Future for Humankind," which was made at the 70th Session of the UN General Assembly on September 28, 2015 at the UN New York Headquarters, signaled transition to structuring and systemization of the cognitive sphere "shared future for humankind" (Xi 2015). The cognitive field of the ideas and images received clear-cut reference points within the framework of diplomatic discourse and was given a conceptual definition.

The Chinese president defined key frames of the concept "shared future for humankind":

The frame "policy" — establishment of partner relations on an equal footing and mutual understanding;

The frame "security" - creating a safe architectonics based on truth and equity, joint construction and shared enjoyment of the results;

The frame "economy" - aspiration for an open, innovative, inclusive and mutually beneficial development, building a normative system, in which effectiveness and equity are in balance.

The frame "culture"-facilitating exchanges between civilizations based on the principles "agree to differ," "acceptance of one and all."

The frame "environment"-building an environmental system of respect for nature and "green" development.

It should be noted that China's leadership has read its own meaning and vision of the future of mankind into frames with general notions, such as policy, economy, security, culture, environment. The idea of "common" and "joint" dominated the conceptual solution, which linked the figurative and metaphoric dimension of the cognitive sphere "shared future for humankind" with its conceptual dimension.

The cognitive space of "shared future for humankind" reveals itself on the communicative plane. 


\subsection{Pragmatic Approach}

The communicative plane is where a few problems are solved: For the sake of what was the concept "shared future for humankind" created? For what purpose was the concept meaning expanded and deepened? Why was it structured and classified in the figurative, theoretical, conceptual and axiological field?

On the communicative plane, promotion of the concept "shared future for humankind" required a clear-cut articulation of the goals and task planning, selection of problem-solving ways and ways of target achievement. Language analysis of the concept already pointed to its global goal-setting, the tasks at hand were related to international activities, and ways to address them were linked to foreign policy work, with diplomatic discourse being an instrument to achieve that goal.

Thus, putting forward the concept "shared future for humankind" since the ascendance of Chinese president Xi Jinping to the presidency in 2012 indicated that China was making a transition from regional goals to global ones in international affairs. This transition from Deng Xiaoping's strategic guidelines aiming at the country's internal development and establishing priority of economy over politics to a more active involvement in global affairs and putting forward a global agenda was slow. Tasks were set in a successive order. Backing by discourse was provided at the level of the president of the People's Republic of China, the premier of the State Council and other state councilors, the International Liaison Department of the CPC Central Committee, academic institutes and universities, think tanks and individual experts.

The goal of putting forward the concept "shared future for humankind" was to elevate China's foreign policy product to a global level. That product would become a bid for China's stronger political role worldwide and would contribute to the country's involvement in global economic and political management, commensurate to its economic power.

To achieve that goal, tasks were worked out to promote that concept at a bilateral, regional and global level and to seek its international, and, afterward, international legal recognition.

As Wang argues, China's diplomatic discourse is determined to inject Chinese concepts and ideas into the narratives of world affairs. The President of the PRC Xi Jinping has been especially energetic in selling his new concepts and discourse to the world.

Amidst an almost total control of the international space by Western media, another important task was to provide discursive support to the promotion of the Chinese global concept.

From our point of view, in its evolution, the concept "shared future for humankind" had gone through five stages before it became the key foreign policy tool for the implementation of China's global strategy.

First stage: The idea of "shared future" (later, it became the foundation of the concept "shared future for humankind") first emerged in the rhetoric of Chinese leadership even before October 2012. Before being launched on the global level, it was tested in an ideological discussion between Beijing and Taipei. 
The idea of "shared future between two shores" put forward by Chinese leadership was proposed as a common formula for the relationship during the rule of Ma Ying-jeou's Taiwanese administration between 2001 and 2016-as an opposition to the concept "common life and destiny" of Lee Teng-hui (1988-2000) and Chen Shui-bian (2000-2007), who were advocating Taiwan's localization and de facto separation from continental China.

The idea of "shared future" first emerged in the political rhetoric of Chinese leadership in 2007, when this formula was used by Chinese President $\mathrm{Hu}$ Jintao, who discussed the relationship of continental China and Taiwan. The idea was further developed in the 2011 "White Paper: China's Peaceful Development," where it was officially unveiled for the first time as a reflection of an important trend toward economic globalization, which impacts international relations (Zhongguo 2011). State Councilor Dai Bingguo in his op-ed for the newspaper Le Figaro and Hu Jintao in the 2012 report at the 18th National Congress of the Communist Party of China also extensively used that term (Dai 2011; Hu 2012). Thus, even before Xi Jinping came to power, the idea of "shared future for humankind" had been an item in the diplomatic luggage of Chinese leadership. It was present both in official documents and in statements of Chinese leaders.

Second stage: from March 2013 to September 2015-evolution of the idea and its transformation into the concept "shared future for mankind." During his first visit to Moscow in March 2013, Chinese President Xi Jinping made a statement at the Moscow State Institute of International Relations, in which he presented his interpretation of the Chinese project for the world. He said, in particular: "It is a world where countries are linked with and dependent on one another at a level never seen before. Humankind, by living in the same global village in the same era and on the same earth where history and reality meet, has increasingly emerged as a community with a shared future in which you are in us, and we are in you" (Guanyu 2018). The idea of "shared future" became surrounded by images and metaphors, which deepened its meaning, but at that stage, the idea was more like a concept, a pre-notion.

At that stage, the idea of "shared future" was promoted at the regional level. Its regional dimension was articulated in Xi Jinping's statements at the Asian Forum in Boao on April 7, 2013 and at the Conference on Diplomatic Work with Neighboring Countries on October 24, 2013. The Chinese president said that awareness of shared future must take root in China's neighboring nations, thus pointing out to the project's development vector for the first time. One remarkable landmark in the evolution of that idea was Xi Jinping's speech delivered at the Brazilian parliament in July 2014 , in which he voiced an initiative of building a shared future for humankind. It was the first time when the global scale of the Chinese initiative was identified (This is... 2018).

At the second stage, the idea of "shared future" acquired a metaphoric and symbolic depth of a concept and spatial boundaries, which expanded from bilateral relations to regional ones (neighboring countries) and, further on, to a global scale.

The third stage was marked by Xi Jinping's statement entitled "Working Together to Forge a New Partnership of Win-win Cooperation and Create a Community of 
Shared Future for Humankind," which was made at the 70th Session of the UN General Assembly on September 28, 2015 at the UN New York Headquarters.

The Chinese president described an already developed concept of "shared future for humankind," in which he identified key spheres of its evolution: politics, security, economics, culture and environment.

Thus, the cognitive space "shared future for humankind" was built, which included the following essential elements: idea, concept, notion and the concept "shared future for humankind" (Xi 2015).

In his public statements of 2015 and 2016, Xi Jinping was publicizing the instrument of "shared future for humankind" far and wide and upgraded its status to China's main foreign policy premise, alongside building "international relations of a new type, with collaboration and a win-win situation at their core." Even the transcontinental Belt and Road Initiative was regarded as practical implementation of the foreign policy strategy of "shared future for humankind."

An important addition to the cognitive space "shared future for humanmankind" was the Chinese president's statement made at the UN Geneva Headquarters on January 18, 2017. In his keynote speech entitled "Work Together to Build a Community of Shared Future for Humankind," Xi Jinping articulated the underlying concept of the cognitive space "shared future for humankind" in detail and in a systemic fashion. One special feature of that speech was the fact that Xi Jinping outlined the historical depth and the temporal scale of the cognitive space. Building a "shared future for humankind" he defined as ("the topic of this era"), which is a concept denoting a time period embracing from a few dozen to hundreds of years, and, by scale, inferior only to periodization of formations. As Xi Jinping noted, "Pass on the torch of peace from generation to generation, sustain development and make civilization flourish: this is what people of all countries long for" (Xi 2017).

At the third stage, creation of the cognitive space "shared future for humankind" was largely completed, its temporal and spatial parameters were defined, the internal structure and its elements were worked out. The Chinese project of "shared future" was presented and was tested at UN global institutions in New York and Geneva.

The fourth stage is linked to the practical implementation of the project of "shared future for humankind" in terms of its further promotion at all levels and deepening of its theoretical foundation.

The space "shared future for humankind" became the main goal of the Belt and Road Initiative, which the Chinese president mentioned at the high-level Belt and Road Forum for International Cooperation, which was held within the framework of the Belt and Road Initiative in May 2017. In his statement at a round-table discussion of the forum, he said that "in the context of international cooperation to build the Belt and Road Initiative [...], everyone will be moving forward toward a shared future for humankind" (People's Daily 2017). According to Xi Jinping, this was his first intention when he came up with that initiative and it is his ultimate goal that he is hopeful of achieving through that initiative. Thus, the Belt and Road Initiative is a practical implementation of the Chinese project of "shared future for humankind" at the transregional level.

Deepening the global dimension of the project of "shared future for humankind" implied proposals on matters of international security. In his speech at the opening 
of the INTERPOL 86th General Assembly in Beijing in September 2017, the Chinese president advocated building a system of common security within the framework of a shared future for humankind.

In October 2017, the 19th National Congress of the Communist Party of China took place. The congress summarized the party's activities and those of its General Secretary Xi Jinping during the reporting period and outlined the vision for future work. The project of "creating a shared future for humankind" was widely covered in the Chinese leader's report.

Xi Jinping articulated "five priorities" in building a shared future for humankind:

- [all countries] "should respect each other, discuss issues as equals, resolutely reject the Cold War mentality and power politics";

- [all countries] "should commit to settling disputes through dialogue and resolving differences through discussion, coordinate responses to traditional and nontraditional threats, and oppose terrorism in all its forms";

- [all countries] should "promote trade and investment liberalization and facilitation, and make economic globalization more open, inclusive, and balanced so that its benefits are shared by all";

- [all countries] "should respect the diversity of civilizations," and, "in handling relations among civilizations," "replace estrangement with exchange";

- [all countries] "should be good friends to the environment, cooperate to tackle climate change" (Zhang 2017).

The congress reinforced the global component of the space "shared future for humankind," identified global threats and challenges, made an attempt to oppose China's own global project to the Western one.

One important outcome of the 19th National Congress of the Communist Party of China was amending the Constitution of the Communist Party of China by incorporating the idea of "work to build a community with a shared future for humankind" as a foreign policy goal of China's Communist Party. In March 2018, at the first session of the 13th National People's Congress, a resolution was passed to amend the nation's Constitution by including into it the formula about building such a future as the state's main foreign policy goal during Xi Jinping's tenure in office.

Having upgraded the project of "shared future for humankind" to being adopted by institutions inside the country, Chinese leadership began to make an effort to make it relevant at the international level. One goal of the foreign policy activities pursued by Xi Jinping and the diplomatic machine was to have that project included in the international legal system and, afterward, to see Chinese ideas transform into international legal rules.

Key people who played a special role in disseminating the project of "shared future for humankind" worldwide were Xi Jinping, China's President, Li Keqiang, Premier of the State Council of the People's Republic of China, Wang Yi, Minister of Foreign Affairs, and others. They have promoted the concept since 2013 in bilateral and multilateral formats, both at regional and global levels.

Beginning from 2017, the Chinese project of "shared future for humankind" has been featured in a number of UN documents. 
On February 10, 2017, at the 56th session of the UN Commission for Social Development, a draft resolution entitled "Social dimensions of the New Partnership for Africa's Development" was discussed, in which the formula "to create a shared future" appeared for the first time on the initiative of the Chinese side.

On March 17, 2017, when the UN Security Council was passing a resolution on the situation in Afghanistan, it stressed "the crucial importance of advancing regional cooperation in the spirit of win-win cooperation as an effective means to promote security, stability and economic and social development in Afghanistan and the region to create a community of shared future for humankind."

On March 23, 2017, at the 34th session, the UN Human Rights Council passed two resolutions: "Question of the realization in all countries of economic, social and cultural rights" and "The right to food," which pointed out for the first time to the need to "build a community" "of shared future for all human beings" and "shared future for humankind," respectively.

On November 2, 2017, the Committee of Disarmament and International Security, or the First Committee, of the 72nd Session of UN General Assembly concluded its meetings. The committee's resolution included China's idea of building a shared future for humankind. On that occasion, Hua Chunying, the official spokesperson of China's Ministry of Foreign Affairs, said at a regular press conference that China's idea "has gained growing support globally and been increasingly echoed in the UN agenda."

On March 23, 2018, at the Palace of Nations in Geneva, the UN Human Rights Council adopted, at its 37th session, a resolution entitled "Promoting mutually beneficial cooperation in the field of human rights" proposed by China. For the first time, two important ideas were simultaneously incorporated in a UN resolution: "fostering international relations" of new type and "building a community of shared future for human beings."

In our opinion, incorporation of the idea of "shared future for humankind" in UN resolutions marked the initial stage of international recognition of the Chinese global project.

The concept of a community of shared destiny has received a new development in the age of the pandemic of COVID-19. During telephone conversations with leaders of other countries and meetings with foreign representatives, during a general discussion at the 75th session of the UN General Assembly in September 2020, President Xi Jinping repeatedly mentioned the concept of a community of shared future for humankind, emphasizing that China stands on protecting the health and life of not only its citizens, but also has a high degree of responsibility for the safety of global public health (Xinhua 2020).

\section{Conclusion}

The discussions of well-known Chinese scholars showed that the issue of China's diplomatic discourse were of immediate interest both for the top echelons of government and for experts of the academia. China's leadership gave a required impetus 
to the examination of the topic, and the scholars proposed relevant models and solutions.

Chinese academia arrived at the conclusion that studies of the issue of diplomatic discourse have an important theoretical and applied meaning in today's world. When developing discourse models, it is necessary to take into account best Western practices, but China's traditional culture must remain a priority. Its achievements must be skillfully combined with contemporary exigencies of international life. Comprehension of Chinese diplomatic discourse is the result of active professional work aimed at promotion of the Chinese language and culture overseas. Effectiveness of diplomatic discourse depends to a large extent on availability of well-developed discourse formulas, on mastering discourse technologies, on the use of discursive strategy and tactics in diplomatic practice.

In the case of the Chinese project of "shared future for humankind," we have analyzed the main foreign policy discourse instrument of Chinese diplomacy in a new era.

It represents a complicated multilayered and compound construct that consists of traditional and modern ideas, concepts and notions, which, put together, form a multidimensional and structured space-and-time field.

In that case, the Chinese project of "shared future for humankind" was examined on three planes.

On the sociolinguistic plane, we identified the semantic form of "shared future for humankind" as a concept, which represents a transition from an idea to a notion. Since it consists of three parts, it is compound. It has been analyzed within the framework of a hermeneutic circle: from individual parts to a whole and from a whole to individual parts. We have demonstrated the etymological base of the concept. One essential moment for comprehending the concept was analysis of its translations into foreign languages that have their own peculiarities in its interpretation.

On the cognitive plane, we have shown how the cognitive space "shared future for humankind" is built from images, ideas, concepts and notions. That space has its spatial and temporal parameters, an internal structure and an open-end system that can see new elements attached to it. It is on the cognitive plane that we are able to comprehend the construct, taking into account its internal and external contexts.

On the pragmatic plane, within the framework of discursive pragmatics, the project of "shared future for humankind" was investigated as the main instrument and goal of China's foreign policy. We have shown the stages of the project evolution and its practical implementation.

The problem of comprehending Chinese discourse is a multilevel and complicated issue underpinned by figurative and symbolic semantics, divergent translations into foreign languages, multidimensionality of the cognitive sphere and versatility of communication.

In addition, one of the main problems, why the Western countries do not comprehend Chinese diplomatic discourse and give their own interpretation to its terms still remains the problem of the lack of mutual trust. Many Chinese initiatives, in 
particular "the community of the shared future of humankind," are perceived in the West with great distrust as part of China's expansionist policy.

In our opinion, at present, in the "struggle for discourse" Western countries, particularly the USA, are trying to solve the problem precisely through confrontation and from a position of strength, that is, to force China to "play by its own rules" and use its own discourse. In this case, it will become "a game on the Western world's field" and according to its rules, which will lead to the complete dominance of Western discourse and Western languages in it.

This is not possible for the Chinese leadership for a number of reasons:

- Historical (a similar situation was already observed at the end of the nineteenth century, however, China overcame "inequality" of the Western countries on its territory);

- Political (since its foundation in 1949, the PRC has been fighting for its $100 \%$ subjectivity and prioritizing the principle of non-interference in its internal affairs);

- Economic (being the second-largest economy in the world, China cannot "play by someone else's rules");

- Cultural and civilizational (the transition to Western discourse will mean a complete departure from the hieroglyphic code of civilization, that is, from its foundation).

The question arises: how to solve the problem of trust in relations between China and Western countries?

First of all, the problem of trust is solved through interaction. For the development of interaction and movement toward cooperation, it is necessary to strengthen mutual understanding, which is possible only through mutual respect and mutual control.

In our opinion, confrontation will only lead to a rollback from existing boundaries, to enmity and xenophobia both in China and in the world.

For the Western countries, it's very important to understand China's diplomatic discourse. Chinese diplomatic discourse shows how China promotes its own perception of the world at the international level using its specific strategic thinking. It's completely different from that in the West. As noted by the famous US diplomat and researcher H. Kissinger, Chinese and Western strategists have different goals: the former strive to achieve a relative advantage, the latter-to complete victory. For clarity, he gives a comparison of the Chinese game of "weiqi" with Western chess. The game, the oldest in the history of the Chinese, is called "weiqi," writes H. Kissinger (Kissinger 2011).--If chess is a game for a decisive victory, then "weiqi" is a game of a protracted campaign. $<\ldots$. If a chess player seeks to destroy his opponent's pieces with a series of frontal blows, then a talented "weiqi" player goes to "empty" places on the board, gradually reducing the strategic potential of the opponent's stones. Chess develops simplicity of thinking, "weiqi”-_strategic flexibility." 


\section{Declarations}

Conflict of interest On behalf of all authors, the corresponding author states that there is no conflict of interest.

\section{References}

Cao, Zhijian. 2017. Global Human Rights Governance from the Perspective of the Community of Shared Future for Mankind: Human rights Challenges faced by the Community of Shared Future for Mankind. Human Rights 2: 40-47.

Dai, Bingguo. 2011. Jianchi heping fazhan yu geguo tongzhou gongji, hezuo gongying [To Adhere to Peaceful Development, to Act with All the States in One Direction, to Seek Cooperation and Winwin]. http://www.gov.cn/ldhd/2011-09/22/content_1954365.htm. Accessed 16 January 2021.

Guanyu renlei mingyun gongtongti Xi Jinping shuji zheyang shuo [This is What the President Xi Jinping Said about a Community of a Shared Future for Humankind]. 2018. http://www.ccdi.gov.cn/toutiao/ 201804/t20180409_169547.html. Accessed 4 October 2020.

Guo, Yezhou. 2018. Gongjian renlei mingyun gongtongti shi yi xiang weida de shiye [Creating a community of the common destiny for mankind - is a great ides]. Guangming ribao. http://news.sina.com. cn/o/2018-03-27/doc-ifysrrht5651339.shtml. Accessed 22 July 2020.

$\mathrm{Hu}$, Jintao. 2012. Jianding bu yi yanzhe zhongguo tese shehui zhuyi daolu qianjin wei quanmian jiancheng xiaokang shehui er fendou-zai zhongguo gongchandang di shiba ci quanguo daibiao dahui shang de baogao [Firmly March on the Path of Socialism with Chinese Characteristics and Strive to Complete the Building of a Moderately Prosperous Society in All Aspects. Report to the 18th National Congress of the Communist Party of China]. http://news.china.com.cn/politics/201211/20/content_27165856.htm. Accessed 12 October 2020.

Kissinger, Henry. 2011. On China. Penguin Books; Reprint edition (April 24, 2012).

Mardell, Jacob. 2017. The "Community of Common Destiny" in Xi Jinping's New Era. The Diplomat. https://thediplomat.com/2017/10/the-community-of-common-destiny-in-xi-jinpings-new-era/. Accessed 13 September 2020.

Su, Changhe. 2015. Rang women lai wushi de tan tan ruhe tisheng zhongguo waijiao huayu nengli [Let's talk in a businesslike way about how we can increase the possibilities of China's diplomatic discourse]. Pengpai xinwen [Pengpai news]. https://www.thepaper.cn/newsDetail_forward_1334643. Accessed 5 August 2020.

Wang, Jianwei. 2018. Xi Jinping's “Major Country Diplomacy:” A Paradigm Shift? Journal of Contemporary China 1-16. https://doi.org/10.1080/10670564.2018.1497907.

Xi Jinping zhuxi 'Gongshang gongzhu renlei minhyun gongtongti' gaojibie huiyi bing fabaio zhuzhi yanjiang [Xi Jinping's Keynote Speech 'Work Together to Build a Community of a Shared Future for Humankind]. 2017. http://www.xinhuanet.com/world/2017-01/19/c_1120340049.htm. Accessed 3 October 2020.

Xi Jinping zai di qishi jie lianheguo dahui yiban xing bianlun shi de jianghui [Xi Jinping's Speech at the General Debate of the 70th UN General Assembly]. 2015. http://www.xinhuanet.com/world/201509/29/c_1116703645.htm. Accessed 3 October 2020.

Xinhua News Agency. 2020. Full text of Xi's statement at the General Debate of the 75th Session of the United Nations General Assembly. http://www.xinhuanet.com/english/2020-09/23/c_139388686. htm. Accessed 18 September 2020.

$\mathrm{Xu}$, Jin. 2015. Weishenme baoyuan Zhongguo waijiao nandong de zongshi xifang ren? [Why complaining about China's foreign policy is always difficult for Western people?]. Pengpai xinwen [Pengpai news]. https://www.thepaper.cn/newsDetail_forward_1332594. Accessed 3 October 2020.

Zhang, Feng. 2015. Weishenme Zhongguo de waijiao huayu zhenme nandong? [Why is China's diplomatic discourse so difficult to comprehend?] Pengpai xinwen [Pengpai news]. http://www.thepaper. cn/newsDetail_forward_1331004. Accessed 3 October 2020.

Zhang, Zhizhou. 2015. Zhongguo waijiao huayu baochi heli de "nandong"ba! [Let's make China's diplomatic discourse "difficult to comprehend"]. Pengpai xinwen [Pengpai news]. http://www.thepaper. cn/newsDetail_forward_1334910. Accessed October 2019. 
Zhang, Lili. 2017. Wei goujian renlei mingyun gongtongti fendou [Combat for the Creation of a Community of a Shared Future for Humankind]. http://www.71.cn/2017/0420/944540.shtml. Accessed October 2019.

Zhang, Denghua. 2018. The Concept of "Community of Common Destiny” in China's Diplomacy: Meaning, Motives and Implications. Asia \& the Pacific Policy Studies 5 (2): 196-207.

Zhao, Xiaochun. 2018. In Pursuit of a Community of Shared Future: China's Global Activism in Perspective. China Quarterly of International Strategic Studies 04 (01): 23-37. https://doi.org/10.1142/ s2377740018500082.

Zhongguo heping fazhan baipishu [White Paper "China's Peaceful Development”]. 2011. http://www. scio.gov.cn/zfbps/ndhf/2011/Document/1000032/1000032_4.htm. Accessed 11 August 2020. 